\title{
A Digital Security System with Door Lock System Using RFID Technology
}

\author{
Gyanendra K Verma \\ Indian Institute of Information Technology \\ Allahabad-India
}

\author{
Pawan Tripathi \\ Indian Institute of Information Technology \\ Allahabad-India
}

\begin{abstract}
RFID, Radio Frequency Identification is an inexpensive technology, can be implemented for several applications such as security, asset tracking, people tracking, inventory detection, access control applications. The main objective of this paper is to design and implement a digital security system which can deploy in secured zone where only authentic person can be entered. We implemented a security system containing door locking system using passive type of RFID which can activate, authenticate, and validate the user and unlock the door in real time for secure access. The advantage of using passive RFID is that it functions without a battery and passive tags are lighter and are less expensive than the active tags. A centralized system manages the controlling, transaction and operation task. The door locking system functions in real time as the door open quickly when user put their tag in contact of reader. The system also creates a log containing check-in and check-out of each user along with basic information of user.
\end{abstract}

\section{General Terms}

Ubiquitous computing, Security

\section{Keywords}

RFID, Door locking system, Secure Access

\section{INTRODUCTION}

RFID, Radio Frequency Identification is a fundamental and inexpensive technology that enables wireless data transmission [1]. This technology has not been very often used in industry due to lack of standardization among the manufacturing companies earlier. RFID technologies are efficient [2] and secure compare to other network [3]. With RFID, wireless automatic identification takes a very specific form: the object, location, or individual is marked with a unique identifier code contained with an RFID tag, which is in some way attached to or embedded in the target [6]. RFID is not a single product but a comprehensive system, a typical RFID system include three basic elements: RFID tag (transponder), reader (transceiver) and back-end application system (or database), which demands the support of the computer network. The software is used for management, controlling, transaction, operation and maintaining record of the various users.

A digital door locking system is also implemented and governed by RFID reader which authenticate and validate the user and open the door automatically. It also keeps the record of check-in and check-out of the user. It's very important to authenticate the user before entering into a secure space and RFID provide this solution. The system enables user to check-in and check-out under fast, secure and convenient conditions. The system include door locking system which open when the user put their tag in contact with reader and the user information matched with the information already stored in database. The RFID controls the opening and closing of the door. In this study we utilize RFID technology to provide solution for secure access of a space while keeping record of the user. We used passive type of rfid here. The passive types of rfid are battery-less and they obtain power to operate from reader. The major advantages of passive rfid are its cost effective and small in size. Due to above advantages, it is widely use by inventory tracking technology [4]. Current antenna technology makes it possible to smaller in size [5].

Figure 1: A typical RFID system

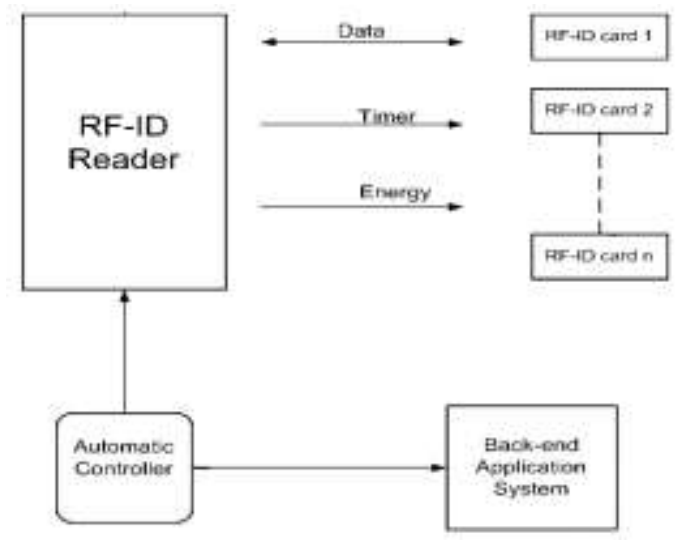

\section{PROPOSED STRUCTURE AND DESIGN OF THE SYSTEM}

In this study, we proposed a security system contains door locking system using passive type of rfid. The system is implemented in three spaces using central database system. The secure space located on same or different part of buildings as illustrate in figure1. The system used hardware as well as software. The hardware components are RFID reader, tags, USB connections and connecting cables etc. In addition we have used actuator (stepper motor for this purpose). The proposed scheme is showing in figure2.

The detail of the proposed scheme is showing below:

Step 1: The RFID reader retrieve the information contains by tag as it come in the range of few millimeters from reader. 
Step 2: after receiving the tag information, reader send this information to database for conformation. If it holds, the information stored for further operation.

Step 3: The central server queries to database and retrieve corresponding information after receiving the query from the reader.

Step 4: The reader computes timestamp (date, time) after receiving the reply form server and create a log.

Step 5: Once the tag information verified, the system generates a control signal through parallel port which controls the opening and closing of door by means of steeper motor.

Figure 2: Proposed design of the system

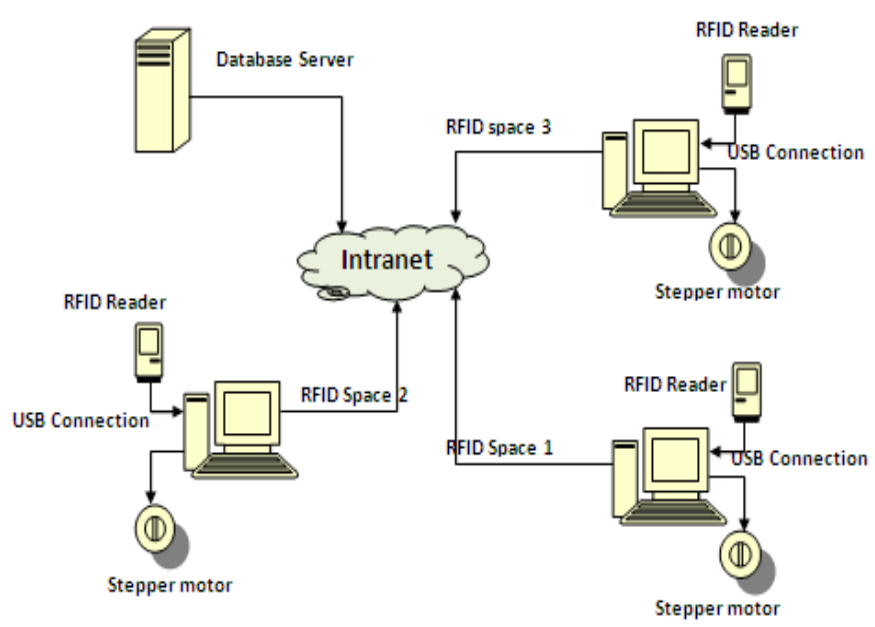

We implement the system using passive tags. The RFID tag is detected when touched or come in the range of few millimeters from reader. The tag is automatically detected by RFID reader in every mille second and reader sent the information containing by tag to the central control though serial port. The central controls already have information of different users registered with system. The signal information coming from RFID reader is matched with the stored information in local as well as central control. When the information matched with the stored information, system displays the information. The information contains details of user as name, id no, category, check-in time, check-out time, date and photo as well. All the coming information of RFID tag gets stored by central control server. System can also generate report of a single user as well as multiple users according to the date, time. Once the tag user authentication is performed, system generates a control signal through parallel port. This control signal goes to a control circuit.

RFID reader was connected to the system through USB port to provide communication between system and RFID reader. The output control signal is generated by system through parallel port which controls the opening and closing of door by means of steeper motor. The technical specifications of the RFID are as follows:
- Power: DC6V, 4 standard AA alkaline batteries

- Read speed: $0.5 \sim 1.0$ second

- Capacity: 100 different cards

- Maximum reading rang: RFID card: less than 30mm

- Card format: For ID card EM.125K

- Door Lock: Motor driven locks and unlock

- Battery life: More than 4,000 times open/close of door

- Low voltage warning: When CPU working voltage is less $4.8 \mathrm{~V}$, the lock can still be opened 200 times before the batteries are replaced

- Door thickness request: $32 \mathrm{~mm} \sim 45 \mathrm{~mm}$

\section{WORKING OF THE SYSTEM}

The system stores all the necessary information about the user. A new user is first registered with the system and the corresponding information is burn in RFID tag. This RFID tag will be accessible through the system. When a registered user comes to the entry point, and put the tag into reader, the system checks whether it is registered user or imposter. If the user is registered one then the tab information is matched with the user information stored in system. The door is open to entry of the user after successful authentication and close automatically after a specified time interval. The check-in information is also stored in the database with date and time. A $\log$ is also generated by the system according to check-in information. User check-in process is depicted in figure 3. Card detection setting is shown in figure 4. Database search is illustrated in figure 5 and output of database entry is illustrated in figure 6 .

Figure 3: User check-in process

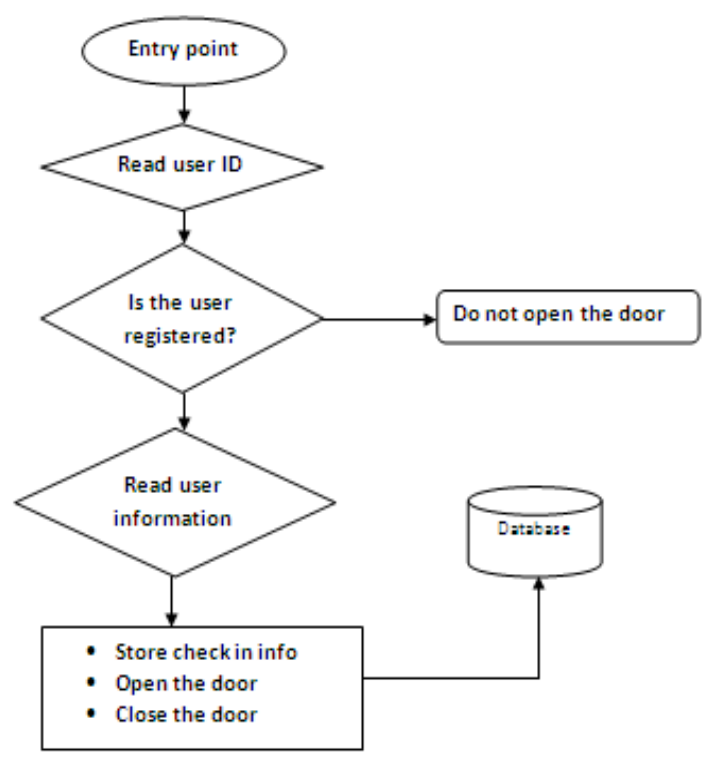

Figure 4: Card Detection 


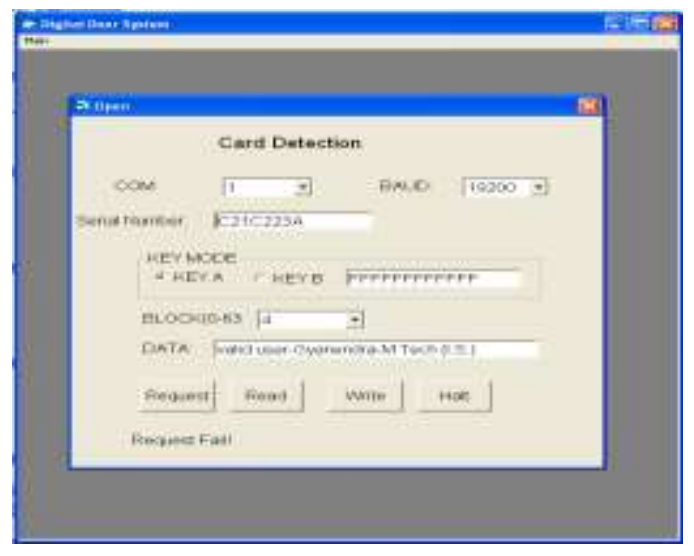

Figure 5: Database Search

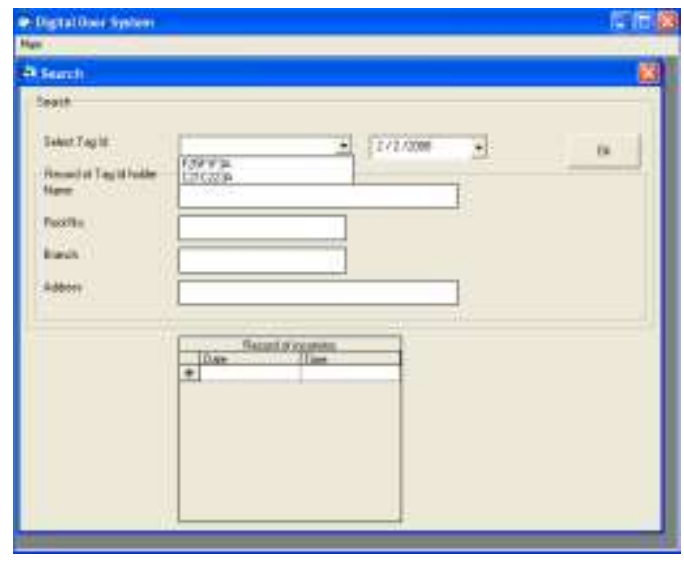

Figure 6: Database Entry

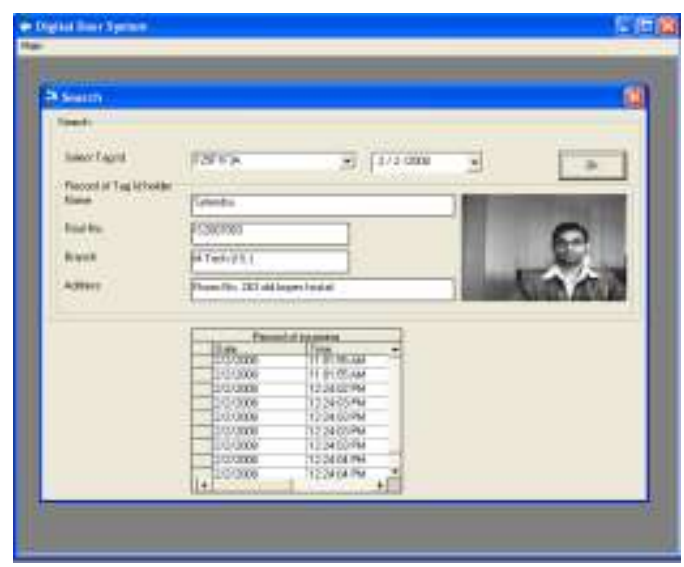

\section{DISCUSSION AND RESULT}

The system has a controller PC which contains the record of the check-in and check-out of the user. User must have RFID tag which contains the personal information of that particular user. A door along with locking system is driven by stepper motor. Stepper motor acts as actuator, which is able to open and close the door in real-time. The RFID Reader detects tag in real-time and open door automatically and closes it again after a specific time interval. In this application, user authentication information is searched on the database first. If the user does not have any previous record registered to the database, the door will not be open thus unauthorized entries will be avoided.

In this work we have successfully implemented security system which can be apply to record attendance in class room of institute or can deploy in secured zone so that only authentic person can enter in secure space. Once the user information matched with information stored in central database system, then user only can enter within the confined place as the door will open only when the tag information match with the database. The system can be deploy in various secure places within a building. The system is also able to maintain the record of a user such as how many time and what time user check-in and which area. All the databases are stored in database server as well as local server. Administrator can access database server remotely through internet or intranet and can see all the records.

\section{CONCLUSION}

In this study, we have implemented a digital security system contains door lock system using passive RFID. A centralized system is being deployed for controlling and transaction operations. The door locking system functions in real time as when the user put the tag in contact with the reader, the door open and the check-in information is stored in central server along with basic information of the user. We utilize RFID technology to provide solution for secure access of a space while keeping record of the user.

\section{REFERENCES}

[1] Zeydin Pala and Nihat Inan, "Smart parking application using RFID technology", RFID Eurasia, ${ }^{\text {st }}$ Annual in RFID Eurasia, 2007.

[2] Zhang, L., "An Improved Approach to Security and Privacy of RFID application System", Wireless Communications, Networking and Mobile Computing. International Conference. pp 1195- 1198, 2005.

[3] Xiao, Y., Yu, S., Wu, K., Ni, Q., Janecek., C., Nordstad, J,” Radio frequency identification: technologies, applications, and research issues" Wiley Journal of Wireless Communications and Mobile Computing, Vol 7, May 2007.

[4] Goodrum, P., McLaren, M., Durfee, A.," The application of active radio frequency identification technology for tool tracking on construction job sites." Automation in Construction, 15 (3), 2006, pp 292-302.

[5] R. Weinstein, "RFID: a technical overview and its application to the enterprise," IT Professional, vol. 7, pp. 27 33, May-June 2005.

[6] Yu-Chih Huang;"Secure Access Control Scheme of RFID System Application", Fifth International Conference on Information Assurance and Security, China, 2009.

[7] S. Shepard, "RFID Radio Frequency Identification", USA, ISBN: 0-07-144299-5, 2005. 